\title{
The barriers against initiating insulin therapy among patients with diabetes living in Yazd, Iran
}

This article was published in the following Dove Press journal:

Diabetes, Metabolic Syndrome and Obesity: Targets and Therapy

\author{
MR Shafie Pour' \\ T Sadeghiyeh ${ }^{2}$ \\ M Hadavi ${ }^{3,4}$ \\ M Besharati ${ }^{5}$ \\ R Bidaki ${ }^{6}$
}

'Department of Internal Medicine, Rafsanjan University of Medical Sciences, Rafsanjan, Iran; ${ }^{2}$ Department of Psychiatry, Research Center of Addiction and Behavioral Sciences, Hahid Sadoughi University of Medical Sciences, Yazd, Iran; ${ }^{3}$ Department of Anesthesiology, Paramedical Faculty, Rafsanjan University of Medical Sciences, Rafsanjan, Iran; ${ }^{4}$ Molecular Medicine Research Center, Research Institute of Basic Medical Sciences, Faculty of Medicine, Rafsanjan University of Medical Sciences, Rafsanjan, Iran; ${ }^{5}$ Rafsanjan University of Medical Sciences, Rafsanjan, Iran; ${ }^{6}$ Research Center of Addiction and Behavioral Sciences, Diabetes Research Center, Shahid Sadoughi University of Medical Sciences, Yazd, Iran
Correspondence: R Bidaki

Taft, Yazd, Iran

Tel +09 8322632003; 8991683416

Email reza_bidaki@yahoo.com
Introduction: The decision to start insulin therapy is often difficult. Determining the barriers against insulin therapy initiation can facilitate care and treatment strategies. The aim of this study was to evaluate the barriers against initiating insulin therapy among patients with diabetes living in Yazd, Iran.

Methods: This descriptive study was conducted on 214 patients referred to the Diabetes Center of Yazd University of Medical Sciences in 2015. Participants were randomly selected, and then they completed the insulin noncompliance questionnaire (20 questions). The percentage of adherence and the factors contributing to nonadherence to insulin therapy were analyzed using descriptive statistics, the Kruskal-Wallis test, and the Mann-Whitney test.

Results: The most prevalent reason for insulin therapy refusal was expecting a new method of diabetes treatment $(54.7 \%)$, followed by requiring someone else to administer the injection (19.2\%), fear of needles, cost, traveling (18.7\%), and stress/emotional problems (18.2\%). Lack of trust in the physician was the least restrictive reason for nonadherence to insulin therapy.

Conclusion: The most common reason given for insulin therapy refusal was the lack of adequate education. Therefore, specialized educational interventions can help minimize barriers and improve patients' outcomes.

Keywords: barriers, diabetes, insulin therapy, Yazd

\section{Introduction}

As a chronic disorder, diabetes mellitus (DM) can change carbohydrate, protein, and fat metabolism. ${ }^{1}$ Diabetes is one of the common causes of death in most developed countries. ${ }^{2}$

According to World Health Organization estimation, 250 million people were living with diabetes in 2014 and the global incidence of diabetes is going to double by $2030 .^{3}$ About 4 million Iranian adults were living with diabetes in 2011 although half of this population was not aware of their disease. ${ }^{4-6}$ It is estimated that by the year 2030, about 9.2 million Iranian individuals will have diabetes. ${ }^{7}$ Type 1 diabetes mellitus is associated with insulin deficiency and is also a consequence of pancreatic $\beta$-cell loss, and it is typically diagnosed in people aged $<30$ years. Type 2 diabetes mellitus (T2DM) is induced due to relative insulin deficiency caused by pancreatic $\beta$-cell dysfunction and insulin resistance in target organs, and typically occurs in people aged $>40$ years. Epidemiology of T2DM is affected by genetic and environmental factors. ${ }^{1}$ Even if diabetes is not fatal, it can cause permanent disabilities, including cardiovascular disease, kidney disease, retinopathy, neuropathy, and peripheral arterial and cerebrovascular diseases. ${ }^{8}$ Diabetes and diabetesinduced complications are major causes of morbidity and mortality which 
substantially contribute to health care costs. ${ }^{9}$ Screening and identifying high-risk individuals and referring them to accredited intervention programs is the responsibility of the clinical sector. Insulin has been identified as the most effective glucose-lowering agent. One of the main barriers against initiating insulin therapy is psychological insulin resistance among patients. ${ }^{10}$ In Mostafavian et al's study, ${ }^{11}$ the most prevalent challenges against insulin therapy in poorly controlled T2DM patients were the pain of insulin injection (78.2\%) and fear of injecting oneself with a needle $(74.5 \%) .{ }^{11}$ Mirahmadizadeh et $\mathrm{al}^{12}$ revealed that the patients' main concerns about insulin therapy were insurance coverage, illiteracy, nondiabetic regimens, misconceptions about insulin therapy, and fear of insulin injection. $^{12}$

As a result, it is crucial to primarily identify patients with poor insulin therapy compliance and to design strategies to remove the underlying barriers against insulin therapy refusal, improve treatment efficacy, achieve better intervention outcomes, and reduce the financial burden of health care costs. Therefore, we conducted this study to investigate the barriers against initiating insulin therapy among patients with diabetes living in Yazd, Iran.

\section{Methods}

This cross-sectional study was conducted on patients with T2DM who referred to Yazd diabetes centers (Iran) in 2015. A specialist confirmed DM based on physical and paraclinical examinations. Inclusion criteria were insulin administration by a specialist physician to continue treatment or for the first time, refused insulin therapy by the patient, and willingness to collaborate in this study. Patients with severe psychiatric disease (in this study, a psychiatrist, with the help of the researcher using Diagnostic and Statistical Manual of Mental Disorders, 4th editioncriteria, assessed the patients with a semistructured interview) and patients undergoing noninsulin therapy were excluded from the study. Written informed consent was obtained from each of the patients.

The necessary sample size was calculated as 189 patients based on the $\mathrm{n}=\mathrm{Z}^{2}{ }_{1-\alpha / 2} p(1-\mathrm{p}) / \mathrm{d}^{2}$ formula, for which, considering the possibility of loss, 220 patients should be evaluated $\left(\alpha=0.05, \mathrm{Z}_{1-\alpha / 2}=1.96, p=0.4, \mathrm{~d}=0.07\right.$ ).

After coordinating with the authorities, the researcher was present in the research environment. After explaining the method and purpose of the study, and obtaining informed consent from the patients, a questionnaire was completed among the diabetic patients referred to the clinic. In the case of children, their parents completed the informed consent and questionnaires.

Data collection was done using a two-part questionnaire. The first part included demographic information such as gender, age, type of diabetes, educational level, and marital status. The second part contained 20 questions on the reasons for insulin noncompliance, which was designed by Habibi et al in 2012. ${ }^{13}$ The reliability of this questionnaire was calculated in Habibi et al's study $(r=0.9)$. Cronbach's alpha in this study was $0.89 .{ }^{13}$ It was scored based on a 5-point Likert scale as follows: (1) strongly disagree, (2) disagree, (3) undecided, (4) agree, and (5) strongly agree. Psychologists and psychiatrists who were faculty members approved the validity of this questionnaire. The reliability of the questionnaire was 0.9 and Cronbach's alpha equaled 0.89. Patients who met the inclusion criteria completed the questionnaire. All analyses were performed using SPSS (version 18). The significance level considered was 0.05 .

\section{Ethical approval}

This manuscript is based on a thesis for achievement of a $\mathrm{PhD}$ degree in medicine. The study proposal was approved by the research department of Rafsanjan University of Medical Sciences. It was approved by the ethics committee of Rafsanjan University of Medical Sciences. We conducted the study in accordance with the Declaration of Helsinki.

\section{Results}

Six of 220 questionnaires were excluded from the study due to incomplete information. Therefore, information from 214 patients was analyzed. Considering gender, 115 participants $(53.7 \%)$ were female and $99(46.3 \%)$ were male. 189 of the participants $(88.3 \%)$ were married. The age range was 6-89 years (mean $\pm \mathrm{SD}$ age $54.3 \pm 13.1$ years) and only $7 \%(\mathrm{n}=15)$ were college graduates. Patients' opinions about the barriers against insulin initiation are shown in Table 1.

The most prevalent cause of insulin therapy refusal was the patients' expectations for new diabetes treatment (54.7\%). However, only $3.3 \%$ of patients expressed a lack of trust in the physician as a reason for refusing insulin therapy. Possible factors influencing patient's nonadherence to insulin therapy are illustrated in Table 2.

Among these factors, gender had a statistically significant association with injection site pain; in other words, females mostly chose this item. Our results revealed that 
Table I Distribution of possible barriers to insulin adherence in diabetic patients

\begin{tabular}{|c|c|c|c|c|c|}
\hline Barrier & $\begin{array}{l}\text { Strongly disagree, } \\
\text { number }(\%)\end{array}$ & $\begin{array}{l}\text { Disagree, } \\
\text { number (\%) }\end{array}$ & $\begin{array}{l}\text { Undecided, } \\
\text { number (\%) }\end{array}$ & $\begin{array}{l}\text { Agree, } \\
\text { number (\%) }\end{array}$ & $\begin{array}{l}\text { Strongly agree, } \\
\text { number (\%) }\end{array}$ \\
\hline $\begin{array}{l}\text { Waiting for a new treatment } \\
\text { method }\end{array}$ & 0 & $19(8.9)$ & $29(13.6)$ & $49(22.9)$ & II 7 (54.7) \\
\hline $\begin{array}{l}\text { Dependence on others due to } \\
\text { insulin use }\end{array}$ & $7(3.3)$ & $109(50.9)$ & $34(15.9)$ & $23(10.7)$ & $41(19.2)$ \\
\hline Fear of needles & $6(2.8)$ & II 5 (53.7) & $26(12.1)$ & $27(12.6)$ & $40(18.7)$ \\
\hline Additional costs & $6(2.8)$ & II 5 (53.7) & $31(14.5)$ & $22(10.3)$ & $40(18.7)$ \\
\hline $\begin{array}{l}\text { Inconvenience of carrying insulin, } \\
\text { especially on trips }\end{array}$ & $7(3.3)$ & $81(37.9)$ & $57(26.6)$ & $29(13.6)$ & $40(18.7)$ \\
\hline Stress or emotional problems & $7(3.3)$ & $98(45.8)$ & $38(17.8)$ & $32(15)$ & $39(18.2)$ \\
\hline Difficulty of keeping insulin & $7(3.3)$ & $91(42.5)$ & $43(20.1)$ & $36(16.8)$ & $37(17.3)$ \\
\hline $\begin{array}{l}\text { Difficulty in injection due to aging } \\
\text { and disability }\end{array}$ & $4(1.9)$ & $113(52.8)$ & $31(14.5)$ & $33(15.4)$ & $33(15.4)$ \\
\hline Injection site pain & $6(2.8)$ & $124(57.9)$ & $30(14)$ & $22(10.3)$ & $32(15)$ \\
\hline Difficult to inject & $6(2.8)$ & $99(46.3)$ & $43(20.1)$ & $35(16.4)$ & $31(14.5)$ \\
\hline Drug unavailability & $10(4.7)$ & $86(40.2)$ & $53(24.8)$ & $35(16.4)$ & $30(14)$ \\
\hline People's opinion & $7(3.3)$ & $113(52.8)$ & $39(18.2)$ & $26(12.1)$ & $29(13.6)$ \\
\hline $\begin{array}{l}\text { Coma due to an unbalanced use } \\
\text { of insulin }\end{array}$ & $6(2.8)$ & $112(52.3)$ & $42(19.6)$ & $25(I 1.7)$ & $29(13.6)$ \\
\hline Being alone & $3(1.4)$ & $126(58.9)$ & $31(14.5)$ & $26(12.1)$ & $28(13.1)$ \\
\hline Sudden death & $9(4.2)$ & $119(55.6)$ & $36(16.8)$ & $23(10.7)$ & $27(12.6)$ \\
\hline $\begin{array}{l}\text { Experiences of others regarding } \\
\text { insulin }\end{array}$ & $5(2.3)$ & $120(56.1)$ & $39(18.2)$ & $23(10.7)$ & $27(12.6)$ \\
\hline $\begin{array}{l}\text { Diabetes has become much } \\
\text { worse }\end{array}$ & $6(2.8)$ & $109(50.9)$ & $54(25.2)$ & $21(9.8)$ & $24(11.2)$ \\
\hline Fear of complications & $9(4.2)$ & $100(46.7)$ & $55(25.7)$ & $26(12.1)$ & $24(11.2)$ \\
\hline $\begin{array}{l}\text { Insulin can hurt family members } \\
\text { because of needle use }\end{array}$ & $5(2.3)$ & $146(68.2)$ & $27(12.6)$ & $19(8.9)$ & $17(7.9)$ \\
\hline Do not have trust in the physician & $15(7)$ & $169(79)$ & $13(6.1)$ & $10(4.7)$ & $7(3.3)$ \\
\hline
\end{tabular}

insulin self-injection capability led to a statistically significant difference with respect to gender and place of residence (rural, urban). Patients without formal education had a higher dependence on others for insulin injection than graduates and this difference was significant $(p=0.007)$.

In addition, misconceptions such as insulin would lead to sudden death, loneliness, and increased costs were more prevalent among patients with lower educational levels than graduates and this difference was significant $(p<0.05)$.

\section{Discussion}

Various factors contribute to DM patients' nonadherence to medication, such as sociodemographic and psychological factors, patient knowledge, as well as therapy-related factors. We distinguished the common barriers faced by DM patients in this investigation. Our results showed that the most common factors that contributed to DM patients' insulin therapy refusal were expecting a new treatment method, dependence on others, and fear of needles. The least expressed factor was trust in the physician.

Numerous studies have explored potential factors associated with insulin refusal in patients with diabetes prior to insulin therapy. ${ }^{11,14-16}$ Mostafavian et $\mathrm{al}^{11}$ showed lower rates of adherence among females, patients with lower educational level, single patients, and patients with more than 1 year of diabetes duration. ${ }^{11}$ Similarly, our findings revealed that education level had a significant association with willingness to use insulin. In other words, illiteracy and low educational level was associated with low adherence to insulin therapy. This finding can be due to the fact that illiteracy can interfere with understanding of the disease and medication to some extent. In contrast to our study, Chen et $\mathrm{al}^{17}$ did not find any significant relation between glycemic control and educational level. ${ }^{17}$ However, a study conducted in 2015 showed that the risk of nonadherence was very high in females and patients 
Table 2 Factors influencing patients' adherence to insulin injection

\begin{tabular}{|c|c|c|c|c|c|c|c|c|c|c|}
\hline \multirow[t]{2}{*}{ Barrier } & \multicolumn{2}{|l|}{ Gender } & \multicolumn{2}{|c|}{$\begin{array}{l}\text { Place of } \\
\text { residence }\end{array}$} & \multicolumn{4}{|c|}{ Level of education } & \multicolumn{2}{|c|}{ Marital status } \\
\hline & Female & Male & Urban & Rural & University & Diploma & $\begin{array}{l}\text { Primary } \\
\text { school }\end{array}$ & Illiterate & Single & Married \\
\hline \multirow[t]{2}{*}{ Fear of needles } & 102.7 & 113.03 & 107.3 & 109.1 & 117.3 & 113.21 & 106.69 & 104.95 & 95.2 & 109.15 \\
\hline & \multicolumn{2}{|l|}{$p=0.18$} & \multicolumn{2}{|l|}{$p=0.89$} & \multicolumn{4}{|l|}{$p=0.56$} & \multicolumn{2}{|l|}{$p=0.24$} \\
\hline \multirow[t]{2}{*}{ Injection site pain } & 96.89 & 119.8 & 106.6 & 115.5 & 129.4 & 122.3 & 108.02 & 95.3 & 102.1 & 108.2 \\
\hline & \multicolumn{2}{|l|}{$p=0.002^{*}$} & \multicolumn{2}{|l|}{$p=0.484$} & \multicolumn{4}{|l|}{$p=0.100$} & \multicolumn{2}{|l|}{$p=0.485$} \\
\hline \multirow[t]{2}{*}{ Additional costs } & 101.3 & 114.7 & 105.5 & 125.5 & 104.7 & 118 & II 4.1 & 88.8 & 111.8 & 106.9 \\
\hline & \multicolumn{2}{|l|}{$p=0.086$} & \multicolumn{2}{|l|}{$p=0.127$} & \multicolumn{4}{|l|}{$p=0.042 *$} & \multicolumn{2}{|l|}{$p=0.707$} \\
\hline \multirow{2}{*}{$\begin{array}{l}\text { Dependence on } \\
\text { others due to } \\
\text { insulin use }\end{array}$} & 102.2 & 113.7 & 107.8 & 104.6 & 126.1 & 110.8 & 114.4 & 84.3 & 116.3 & 106.3 \\
\hline & \multicolumn{2}{|l|}{$p=0.148$} & \multicolumn{2}{|l|}{$p=0.891$} & \multicolumn{4}{|l|}{$p=0.007^{*}$} & \multicolumn{2}{|l|}{$p=0.429$} \\
\hline \multirow{2}{*}{$\begin{array}{l}\text { Hurt family mem- } \\
\text { bers because of } \\
\text { needle use }\end{array}$} & 100.2 & 116 & 110.3 & 82.5 & 128 & 129.4 & 104.5 & 101.9 & 102.4 & 108.2 \\
\hline & \multicolumn{2}{|l|}{$p=0.023^{*}$} & \multicolumn{2}{|l|}{$p=0.016 *$} & \multicolumn{4}{|l|}{$p=0.080$} & \multicolumn{2}{|l|}{$p=0.611$} \\
\hline \multirow[t]{2}{*}{ Sudden death } & 100.2 & 116 & 109.3 & 91.2 & 139.9 & 130.3 & 103.1 & 101.7 & 101.2 & 108.3 \\
\hline & \multicolumn{2}{|l|}{$p=0.042^{*}$} & \multicolumn{2}{|l|}{$p=0.163$} & $p=0.027^{*}$ & & & & $p=0.554$ & \\
\hline Difficult to inject & 94.4 & 112.7 & III.I & 74.07 & 132.7 & 126.3 & 106 & 97.9 & 102.2 & 108.2 \\
\hline & $p<0.00 I^{*}$ & & $p=0.006 *$ & & $p=0.151$ & & & & $p=0.662$ & \\
\hline Fear of & 98 & 118.5 & 110 & 83.7 & 127.4 & 125.1 & 104.6 & 103.1 & 86.4 & 110.3 \\
\hline complications & $p=0.017^{*}$ & & $p=0.048 *$ & & $p=0.279$ & & & & $p=0.053$ & \\
\hline Being alone & 98.8 & 117.6 & 93.8 & 109 & 143.3 & 118.8 & 106.7 & 95.7 & 109 & 107.3 \\
\hline & $p=0.013^{*}$ & & $p=0.230$ & & $p=0.023^{*}$ & & & & $p=0.881$ & \\
\hline Aging and & 97.1 & 119.6 & 108.2 & 100.9 & 130.5 & 120.6 & 109.4 & 92.2 & 102.9 & 108.1 \\
\hline disability & $p=0.004^{*}$ & & $p=0.572$ & & $p=0.062$ & & & & $p=0.663$ & \\
\hline
\end{tabular}

Note: *Significant difference $p<0.05$.

with insufficient education. ${ }^{18}$ Ghadiri-Anari et $\mathrm{a}^{19}$ found that fear of injection was the most frequent reason for insulin therapy refusal and was unrelated to age, sex, and educational level. ${ }^{19}$ The injection device is an important factor in determining adherence to treatment; using traditional insulin syringes in public may result in social rejection or discontinuation. Newer injection devices, compared to syringes, are easier to use and might lessen inconvenience and thus improve adherence. This study identified that fear of needles was the most expressed barrier against insulin therapy initiation. These findings were consistent with previous research, showing that $33 \%$ of patients were anxious about taking their insulin injections. ${ }^{20,21}$ In our study, fear of injection frequency was higher in females and lesser educated patients in comparison with males and higher educated patients. Our findings were in concordance with the literature, where females showed more unwillingness to initiate insulin treatment than males. ${ }^{18,22}$ In another study, children with diabetes experienced more (27\%) injection anxiety when compared with adults. ${ }^{23}$ In a systematic review, Polinski et $\mathrm{al}^{24}$ reported that injection-related problems were of more concern in insulinnaive patients since insulin-treated patients experienced greater side effects, glycemic control, weight gain, and hypoglycemic events. ${ }^{24}$ In this study, the medication cost was cited as a barrier against adhering to insulin therapy, which was in line with findings from other studies on patients with diabetes. ${ }^{15,25-28}$ In a study investigating 
T2DM patients from an economically burdened region, cost was mentioned as a reason for delay in filling prescriptions and discontinuation of oral antihyperglycemic agents. ${ }^{25}$ Creating a health insurance scheme could reduce financial barriers against receiving health care. ${ }^{29}$

We found an association between difficulties in preparing injections and resistance to take the medication. A report on barriers against insulin use by Polonsky et $\mathrm{al}^{30}$ suggested that self-efficacy to manage injections was associated with resistance to using insulin and reduced adherence. ${ }^{30}$ Several trials found other patientrelated barriers such as negative impact on social and work life, injection phobia, and concern about side effects of insulin use such as hypoglycemia. ${ }^{31,32}$ In a systematic review, Brod et al $^{33}$ evaluated 116 peerreviewed articles to assess the impact of psychological insulin resistance on diabetes management. ${ }^{33}$ The aforementioned study revealed that resistance to initiate insulin may be impacted by patients' beliefs and knowledge about glycemic control, negative self-perceptions and attitudinal barriers, fear of side effects, restriction in lifestyle, and social stigma.

In their study, Shah et $\mathrm{al}^{34}$ concluded that the major factors leading to psychological insulin resistance were loss of autonomy, self-injection stigmatization, fear of hypoglycemia, misdirection from the community, cultural acceptability, social phobia, lack of knowledge of the benefits of glycemic control, restriction in lifestyle, pain of injection, uncertainty about treatment benefits, objection to lifelong treatment, noncompliance, restriction in diet, and misdirection from the media. ${ }^{34}$ Jha et $\mathrm{al}^{18}$ found similar factors on conducting a study in India. ${ }^{18}$ The difference in frequencies of reported factors may be attributed to the different geographical and ethnic backgrounds of patients included in these studies. However, a study conducted in 2014 showed that fear of side effects, doubts about effectiveness, inconvenience of taking injections, and cost of insulin therapy were frequently mentioned as reasons against initiating insulin therapy. ${ }^{35}$ Accordingly, conducting medical education programs is suggested to increase knowledge about diabetes management and improve the adherence rate among DM patients.

\section{Conclusion}

The results of this study indicate that diabetic patients are less aware of their illness and have little knowledge about how to treat diabetes. The most common reason given for insulin therapy refusal was the lack of adequate education.
Therefore, specialized educational interventions can help minimize barriers and improve patients' outcomes. There is a need for more awareness in this regard in clinics, health centers, media, and even individual counseling. Insufficient knowledge of insulin implication can result in preventable complications, adverse patient outcome, poor compliance to therapy, instability, and invariably poor glycemic control. Therefore, knowing and removing the barriers about insulin therapy can help adjust the cooperation of patients and acceptance of treatment. Finally, insulin therapy can accelerate quality of life and well-being.

\section{Limitations}

In this study, the economic status and history of hospitalization were not investigated. It is suggested that these factors should be considered in future studies.

\section{Disclosure}

The authors report no conflicts of interest in this work.

\section{References}

1. Wiener C, Fauci AS, Braunwald E, et al. Harrison'S Principles of Internal Medicine, Self-Assessment and Board Review. McGraw Hill Professional; 2008.

2. Weiss M, Steiner DF, Philipson LH. Insulin Biosynthesis, Secretion, Structure, and Structure-Activity Relationships. 2014. Available from: https://www.ncbi.nlm.nih.gov/pubmed/25905258.

3. Keenan DB, Mastrototaro JJ, Voskanyan G, Steil GM. Delays in minimally invasive continuous glucose monitoring devices: a review of current technology. J Diabetes Sci Technol. 2009;3 (5):1207-1214. doi:10.1177/193229680900300528

4. Esteghamati A, Larijani B, Aghajani MH, et al. Diabetes in Iran: prospective analysis from first nationwide diabetes report of National program for prevention and control of diabetes (NPPCD-2016). Sci Rep. 2017;7(1):13461. doi:10.1038/s41598-017-13379-z

5. Azizi F, Gouya M, Vazirian P, Dolatshahi P, Habibian S. The diabetes prevention and control programme of the Islamic Republic of Iran. East Mediterr Health J. 2003;9(5-6):1114-21

6. Azizi F, Guoya M, Vazirian P, Dolatshati P, Habbibian S. Screening for type 2 diabetes in the Iranian national programme: a preliminary report. East Mediterr Health J. 2003;9(5-6):1122-7.

7. Hoseini SM, Kalantari A, Afarideh M, et al. Evaluation of plasma MMP-8, MMP-9 and TIMP-1 identifies candidate cardiometabolic risk marker in metabolic syndrome: results from double-blinded nested case-control study. Metabolism. 2015;64(4):527-538. doi:10.1016/j.metabol.2014.12.009

8. Booya F, Bandarian F, Larijani B, Pajouhi M, Nooraei M, Lotfi J. Potential risk factors for diabetic neuropathy: a case control study. BMC Neurol. 2005;5(1):24. doi:10.1186/1471-2377-5-24

9. Ghanbari A, Yekta ZP, Roushan ZA, Lakeh NM. Assessment of factors affecting quality of life in diabetic patients in Iran. Public Health Nurs. 2005;22(4):311-322. doi:10.1111/j.0737-1209.2005.220 406.x

10. Rossetti P, Porcellati F, Bolli GB, Fanelli CG. Prevention of hypoglycemia while achieving good glycemic control in type 1 diabetes: the role of insulin analogs. Diabetes Care. 2008;31(Supplement 2): S113-S20. doi:10.2337/dc08-s227 
11. Mostafavian Z, Ghareh S, Torabian F, Yazdi MS, Khazaei MR. Data on insulin therapy refusal among type II diabetes mellitus patients in Mashhad, Iran. Data Brief. 2018;18:2047-2050. doi:10.1016/j. dib.2018.04.136

12. Mirahmadizadeh A, Delam H, Seif M, Banihashemi SA, Tabatabaee H. Factors Affecting Insulin Compliance in Patients with Type 2 Diabetes in South Iran, 2017: We Are Faced with Insulin Phobia. Iran J Med Sci. 2019;44 (312):1-10.

13. Habibi R, Soltani M, Habibi G. Factors affecting rejection by diabetics for insulin therapy. Iran $J$ Diabetes and Lipid Disorders. 2012;11(4):366-376.

14. Goyal A, Kumar A. Effect of a diabetes education camp on perception of insulin therapy in patients of type- 2 diabetes mellitus. Med J DY Patil Vidyapeeth. 2018;11(2):137.

15. Farsaei S, Radfar M, Heydari Z, Abbasi F, Qorbani M. Insulin adherence in patients with diabetes: risk factors for injection omission. Prim Care Diabetes. 2014;8(4):338-345. doi:10.1016/j. pcd.2014.03.001

16. Almaghaslah D, Abdelrhman AK, AL-Masdaf SK, Mohammed L, Majrashi BMM, Asiri WM, et al. Factors contributing to non-adherence to insulin therapy among type 1 and type 2 diabetes mellitus patients in Asser region, Saudi Arabia. Biomedical Research. 2018;29 (10): 2090-95.

17. Chen -C-C, Chang M-P, Hsieh M-H, Huang C-Y, Liao L-N, Li T-C. Evaluation of perception of insulin therapy among Chinese patients with type 2 diabetes mellitus. Diabetes Metab. 2011;37(5):389-394. doi:10.1016/j.diabet.2010.12.008

18. Jha S, Panda M, Kumar S, et al. Psychological insulin resistance in patients with type 2 diabetes. J Assoc Physicians India. 2015;63 (7):33-39.

19. Ghadiri-Anari A, Fazaelipoor Z, Mohammadi SM. Insulin refusal in Iranian patients with poorly controlled type 2 diabetes mellitus. Acta Med Iran. 2013;51(8):567-571.

20. Peyrot M, Rubin RR, Kruger DF, Travis LB. Correlates of insulin injection omission. Diabetes Care. 2010;33(2):240-245. doi:10.2337/ dc09-1348

21. Brod M, Pohlman B, Kongsø JH. Insulin administration and the impacts of forgetting a dose. Patient-Patient-Centered Outcomes Res. 2014;7(1):63-71. doi:10.1007/s40271-013-0029-9

22. Nam S, Chesla C, Stotts NA, Kroon L, Janson SL. Factors associated with psychological insulin resistance in individuals with type 2 diabetes. Diabetes Care. 2010;33:1747-1749. doi:10.2337/ dc10-0099
23. Simmons JH, McFann KK, Brown AC, et al. Reliability of the diabetes fear of injecting and self-testing questionnaire in pediatric patients with type 1 diabetes. Diabetes Care. 2007;30(4):987-988. doi:10.2337/dc06-1553

24. Polinski JM, Smith BF, Curtis BH, et al. Barriers to insulin progression among patients with type 2 diabetes: a systematic review. Diabetes Educ. 2013;39(1):53-65. doi:10.1177/0145721712467696

25. Aikens JE, Piette JD. Diabetic patients' medication underuse, illness outcomes, and beliefs about antihyperglycemic and antihypertensive treatments. Diabetes Care. 2009;32(1):19-24. doi:10.2337/dc08-1533

26. Piette JD, Heisler M, Wagner TH. Cost-related medication underuse among chronically III adults: the treatments people forgo, how often, and who is at risk. Am J Public Health. 2004;94(10):1782-1787.

27. Nam S, Chesla C, Stotts NA, Kroon L, Janson SL. Barriers to diabetes management: patient and provider factors. Diabetes Res Clin Pract. 2011;93(1):1-9. doi:10.1016/j.diabres.2011.02.002

28. Hunt J, Rozenfeld Y, Shenolikar R. Effect of patient medication cost share on adherence and glycemic control. Manag Care. 2009;18 (7):47-53.

29. Davies M, Gagliardino JJ, Gray L, Khunti K, Mohan V, Hughes R. Real-world factors affecting adherence to insulin therapy in patients with type 1 or type 2 diabetes mellitus: a systematic review. Diabetes Res. 2013;30(5):512-524. doi:10.1111/dme.12128

30. Polonsky WH, Fisher L, Guzman S, Villa-Caballero L, Edelman SV. Psychological insulin resistance in patients with type 2 diabetes: the scope of the problem. Diabetes Care. 2005;28(10):2543-2545.

31. Karter AJ, Subramanian U, Saha C, et al. Barriers to insulin initiation: the translating research into action for diabetes insulin starts project. Diabetes Care. 2010;33(4):733-735. doi:10.2337/dc09-1184

32. Wong S, Lee J, Ko Y, Chong M, Lam C, Tang W. Perceptions of insulin therapy amongst Asian patients with diabetes in Singapore. Diabetes Res. 2011;28(2):206-211. doi:10.1111/j.1464-5491.2010.03195.x

33. Brod M, Kongsø JH, Lessard S, Christensen TL. Psychological insulin resistance: patient beliefs and implications for diabetes management. Qual Life Res. 2009;18(1):23. doi:10.1007/s11136009-9478-y

34. Shah SMA, Butt Z, Hussain K. Factors leading to psychological insulin resistance among patients with type 2 diabetes mellitus. Ann Pak Inst Med Sci. 2017; 13(3):226-30.

35. Guimarães C, Marra CA, Gill S, Meneilly G, Simpson S, Godoy AL. Exploring patients' perceptions for insulin therapy in type 2 diabetes: a Brazilian and Canadian qualitative study. Patient Prefer Adherence. 2010;4:171. doi:10.2147/PPA.S10178
Diabetes, Metabolic Syndrome and Obesity: Targets and Therapy is an international, peer-reviewed open-access journal committed to the rapid publication of the latest laboratory and clinical findings in the fields of diabetes, metabolic syndrome and obesity research. Original research, review, case reports, hypothesis formation, expert opinion and commentaries are all considered for publication. The manuscript management system is completely online and includes a very quick and fair peer-review system, which is all easy to use. Visit http://www.dovepress.com/testimonials.php to read real quotes from published authors 